\title{
PERBEDAAN PENGARUH METODE LATIHAN PLYOMETRICHURDLE HOPPING DAN STANDINGJUMP TERHADAP KEMAMPUAN JUMPING SERVIS ATAS PADA ATLIT PUTRA USIA 15-17 BOLA VOLI DIVKRA KARANGANYAR 2020
}

\author{
Kodrad Budiyono ${ }^{1}$ Arif Rohman Hakim ${ }^{2}$ \\ Kobuyo212@gmail.com \\ Universitas Tunas Pembangunan Surakarta
}

\begin{abstract}
ABSTRAK
Tujuan penelitian untuk mengetahui Perbedaan Pengaruh Metode Latihan Plyometric Hurdle Hopping Dan Standing Jumping Terhadap Kemampuan Jumping Servis Atasdalam Permainan Bola Voli Pada Atlit Putra Usia 15-17 Club Bola Voli DIVKRA Karanganyar Tahun 2020, dan jika ada perbedaan maka untuk mengetahui mana yang lebih baik antara Latihan Metode Latihan Plyometric Hurdle Hopping Dan Standing Jumping Terhadap Kemampuan Jumping Servis Atas dalam Permainan Bola Voli Pada Atlit Putra Usia 15-17 Club Bola Voli DIVKRA Karanganyar Tahun 2020.

Sampel penelitian adalah pada Pemain Putra Club Bola voli Divkra Karanganyar Tahun 2020dengan jumlah 30 siswa. Pengambilan sampel menggunakan teknik Porpusive Sampling. Rancangan penelitian menggunakan pretest-posttest design. Tes untuk mengetahui kemampuan Jumping Servis Atasbolavoli menggunakan tes Kemampuan Jumping Servis Atas bolavoli menggunakan petunjuk pelaksanaan tes dan pengukuran kemampuan Jumping Servis Atas. Metode analisis data penelitian menggunakan rumus $t$-test.

Hasil analisis data maka simpulan diperoleh: 1) Ada perbedaan Pengaruh Latihan Metode Latihan Plyometric Hurdle hopping Dan Standing Jumping terhadap Kemampuan jumping servis atas dalam permainan bola voli pada atlit putra usia 15-17 club bola voli DIVKRA Karanganyar Tahun 2020. Hal ini dibuktikan dari hasil penghitungan tes akhir masing-masing kelompok yaitu $t_{\text {hitung }}$ $=3,5423$ lebih besar dari pada $t_{\text {tabel }}=2,145$ dengan taraf signifikasi $5 \%$. 2)Latihan Plyometric Hurdle hopping lebih baik pengaruhnya dari pada latihan metode latihan standing jumping terhadap kemampuan jumping servis atas dalam permainan bola voli pada atlit putra usia 15-17 club bola voli DIVKRA Karanganyar Tahun 2020. Berdasarkan persentase peningkatan ketrampilan Kemampuan jumping servis atas menunjukkan bahwa kelompok 1 (kelompok yang mendapat perlakuan dengan Pengaruh Latihan Metode Latihan Plyometric Hurdlehopping) adalah 67.652\%> kelompok 2 (kelompok yang mendapat perlakuan Pengaruh Latihan Standing Jumping) adalah 50.676\%.
\end{abstract}

Kata Kunci : Plyometric Hurdle Hopping, Standing Jumping, Jumping Servis Atas 


\section{PENDAHULUAN}

Pada saat ini olahraga merupakan salah satu kebutuhan yang penting bagi masyarakat, sehingga dapat dilihat di mana-mana orang yang sedang melakukan aktivitas olahraga. Masyarakat sudah tahu bawa olahraga bermanfaat bagi kesehatan dan kebugaran tubuh. Di dalam kehidupan modern manusia tidak dapat dipisahkan dari olahraga, baik untuk meningkatkan prestasi maupun sebagai kebutuhan dalam menjaga kondisi tubuh agar tetap sehat. Bola voli merupakan salah satu cabang olahraga yang memasyarakat di Indonesia. Bola voli sudah sangat populer dan digemari oleh masyarakat, dapat dibuktikan dengan sering dijumpai di desa maupun di kota karena permainan ini dapat dilakukan orang dewasa maupun anak-anak. Akan tetapi pada saat sekarang bola voli terjadi penurunan. Pertandingan-pertandingan bola voli tidak seramai dulu, sekarang sudahjarang. Sedangkan Indonesia mengenal permainan bola voli sejak tahun 1982 pada zaman penjajahan Belanda. Permainan bola voli sudah dikenal di abad pertengahan,khususnya dinegara-negara eropa.

Teknik dasar merupakan hal yang penting dalam suatu cabang olahraga bola voli, karena teknik dasar akan menentukan cara melakukan suatu gerakan dasar yang baik. Keberhasilan melakukan teknik dasar akan menentukan pula keberhasilan dalam melakukan suatu permainan bola voli. Dalam permainan bola voli ada beberapa teknik yang harus dikuasai sebelum bermain bola voli antaralain: Teknik servis (Service), Teknik smash, Teknik menghadang (Block), Teknik passing bawah, Teknik passing atas.

Berdasarkan Observasi yang telah dilakukan di Tim Putra DIVKRA Karanganyar. Saat di lapangan, Tim Putra Divkra Karanganyar banyak yang kurang baik dengan teknik-teknik dasar jumping servis atas, Hal ini terjadi karena posisi kaki dan ayunan tanggan tidak singkron dengan posisi tangan pada saat jumping servis atas tidak tepat denggan bola. Oleh karena itu harus ada metode latihan yang tepat dan guna untuk melatih jumping servis atas. 
TINJAUAN PUSTAKA

\section{Pengertian Permainan Bolavoli}

Permainan bola voli adalah olahraga yang dimainkan anak-anak, orang dewasa baik pria maupun wanita. Menurut PBVSI (2005:1) bola voli adalah olahraga yang dimainkan oleh dua tim dalam setiap lapangan dengan dipisahkan oleh sebuah net. Tujuan dari permainan ini adalah melewatkan bola di atas net agar dapar jatuh menyentuh lantai lapangan lawan dan untuk mencegah usaha yang sama dari lawan. Setiap tim dapat melakukan tiga pantulan untuk mengembalikan bola (di luar perkenaan blok). Bola dinyatakan dalam permainan setelah bola dipukul oleh pelaku servis melewati atas net ke daerah lawan. Permainan dilanjutkan hingga bola menyentuh lantai, bola "keluar" atau satu tim gagal mengembalikan bola secara sempurna. Dalam permainan bola voli, tim yang memenangkan sebuah reli memperoleh satu angka (Rally Point System). Apabila tim yang menerima servis dan memenangkan sebuah reli, akan memperoleh satu angka dan berhak untuk melakukan sevis, serta para pemainnya melakukan pergeseran satu posisi searah jarumjam.

Menurut peraturan PBVSI (2005:1) ciri khas permainan bola voli adalah olahraga yang dimainkan oleh dua tim dalam satu lapangan yang dipisahkan oleh sebuah net. Terdapat versi yang berbeda tentang jumlah pemain, jenis / ukuran lapangan, angka kemenangan yang digunakan, untuk keperluan tertentu. Namun pada hakekatnya permainan Bola Voli bermaksud menyebarluaskan kemahiran bermain kepada orang yang meminatinya.

Permainan bola voli adalah permainan memantul-mantulkan bola(tovolley) dengan menggunakan bagian tangan maupun bagian lengan yang terdiri dari dua regu dan disetiap regu beranggotakan enam orang yang dilakukan dilapangan dengan ukuran tertentu"(Yudiana dan Subroto 
2010:36). Permainan bola voli adalah salah satu cabang olahraga yang menggunakan lapangan yang berukuran $18 \mathrm{~m} \times 9 \mathrm{~m}$, yang dipisah dengan menggunakan jari net dengan ketinggian putra $2,43 \mathrm{~m}$ sedangkan putri $2,24 \mathrm{~m}$, dengan dimaikan oleh 2 tim yang setiap tim terdiri 6 orang pemain.

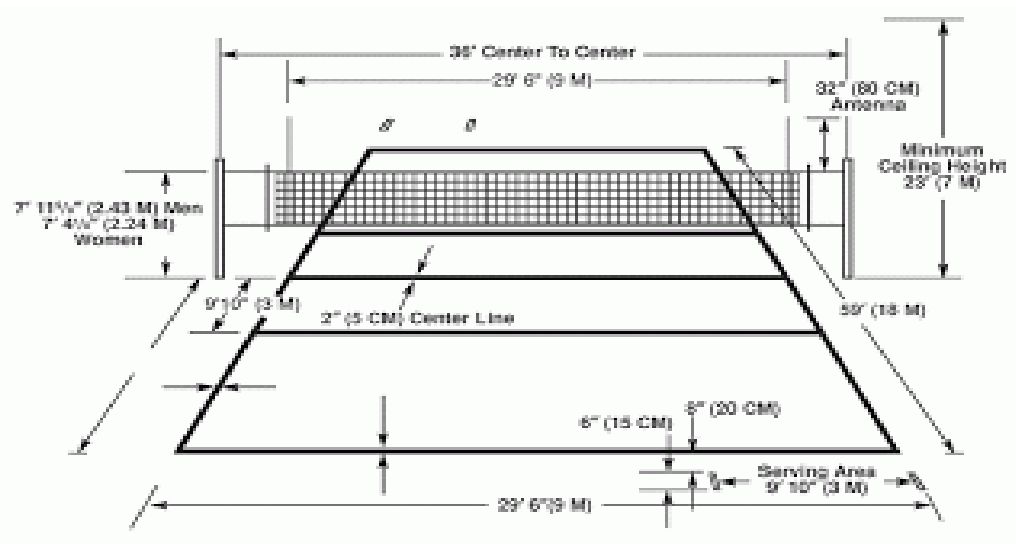

Gambar 1

Skala Lapangan Bola Voli.

http://images.app.goo.gl/dfiGjfibtNfzj65f9

Permainan bola voli dimainkan oleh 2 regu yang setiap regu berusaha menjatuhkan dan memukul bola ke area lawan dengan menggunakan tangan maupun anggota tubuh bagian lain dengan pantulan yang bagus sesuai dengan peraturan yang telah ditetapkan. Peraturan permainan bola voli dimulai dengan melakukan undian yang menentukan tim mana yang melakukan pukulan pertama, pukulan pertama harus melalui jaring atas net dengan kemudian diterima oleh tim lawan selanjutnya tim lawan memainkan bola dengan tangan atau bagian tubuh lain dengan maksimal 3 kali sentuhan, lalu tim lawan berusaha mengembalikan bola kearea pemukul bola pertama dengan melewati atas jaring net,jika lawan gagal mengembalikan bola ke area tim pemukul pertama maka poin di dapat oleh regu yang melakukan pukulan pertama,sebalikmya jika regu pemukul 
pertama gagal menerima bola dari tim lawan maka tim lawan mendapatkan poin dan selanjutnya bola dipukul oleh ditim yang mendapatkan poin.

Kemenangan dalam permainan bola voli ditentukan dengan tim mana yang terlebih dahulu mendapatkan angka 25 setiap set nya untuk set nya sesuai dengan peraturan yang sudah disepakati sebelumnya, jika terdapat poin 24-24 maka akan dilakukan yus atau tim yang mendapatkan poin selesih dua akan menjadi pemenangnya.

\section{Pengertian servis}

Servis adalah pukulan pertama saat permainan bolavoli akan dimulai. Servis dilakukan dibelakang garis permainan area tim dengan pukulan melewati atas jaring net dan masuk kearea lawan. Cara melakukan servis terentang ada yang paling sederhana. komplek dan paling menyulitkan lawan bahkan sampai mematikan permainan lawan ( Subroto dan Yudiana, $2010: 52$ )

Dalam permainan bolavoli terdapat dua macam teknik servis antara lain servis bawah dan servis atas. servis digunakan untuk mengawali pertandingan bolavoli, ada dua macam servis yaitu servis yang dilakukan diatas kepala dan servis yang di dilakukan dari bawah, dalam pegenalan servis biasanya mengunakan servis bawah karena lebih mudah "( Asmara, $2010: 52$ ).

1) Servis Bawah

Servis bawah merupakan salah satu jenis servisyang diajarkan di sekolah dan merupakan jenis servis yang di lakukan oleh pemula."salah satu ciri servis bawah adalah bolanya melambung, sehingga bagi para pemain yang sudah memiliki keterampilan tinggi sangat mudah menerima servis model ini " ( Subroto dan Yudiana $2010: 25$ ). 
Servisbawah merupakan salah satu macam servis yang banyak digunakan oleh pemula yang baru saja mengenal tentang permainan bola voli. Saat melakukan servisbawah ada 3 posisi yang harus dipelajari antara lain sikap permulaan, gerak pelaksanaan dan gerak lanjutan .

a) Sikap permulaan

Dalam melakukan servis bawah pemain berdiri dibelakang garis permainan ,dengan pemain menghadap ke lapangan permainan, salah satu kaki terkuat berada di depan, bila mengunakan tangan kanan untuk memukul maka kaki kanan berada di depan begitu sebaliknya, bola di pegang oleh salah satu tangan kanan ataupun kiri, tangan pemukul megengam, dan lutut sedikit di tekuk.

b) Sikap pelaksanaan

Saat sikap pelaksanaan bola dilambung kan setimggi $10 \mathrm{~cm}$ $20 \mathrm{~cm}$. saat melambungkan bola salah satu tangan ditarik kebelakang, kemudian saat bersamaan bola sampai didepan perut ayunkan tangan kedepan sehingga mengenai bola bagian belakang.

c) Gerakan lanjutan

Gerakan kaki untuk menjaga keseimbangan agar siap memasuki lapangan permainan, dan siap untuk memainkan bola yang dikembalikan oleh lawan.

2) Servis Atas

Salah satu jenis servis yang dilakukan oleh pemain yang memiliki keterampilan tinggi dan biasanya di lakukan di pertandingan. "Servis atas, jenis servis yang awalannya melambungkan bola keatas seperlunya, lalu server melompat dan menyambut bola dengan memukul bola dengan ayunan tangan dari atas " (Anandita $2010: 25$ ). Ada beberapa variasi dalam servisatas antara lain floating, jumping 
dan masih banyak lagi, dalam melakukan servis atas ada beberapa langkah yang harus di perhatikan antara lain sikap permulaan, gerakan pelaksanaan dan gerakan lanjutan.

a) Sikap permulaan

Saat sikap permulaan servis atas pemain berada di belakang garis lapangan permainan, salah satu kaki berada didepan, kaki kanan berada didepan bila menggunakan tangan kanan jika menggunakan tangan kiri makan kaki kiri berada didepan, selanjutnya bola dipegang oleh salah satu tangan kanan maupun kiri.

b) Gerakan pelaksanaan

Dalam gerakan pelaksanaan bola dilambungkan keatas lebih tinggi dari jangkauan tangan pemukul, tangan pemukul diayunkan segera untuk memukul bola saat dalam jangkauan tangan dengan perkenaan bagian belakang bola, sehingga bola berjalan memotong garis tengah bola.

c) Gerakan lanjutan

Gerakan lanjutan tangan pemukul segaris tengan gaya yang di hasilkan, kaki yang berada dibelakang melangkah ke depan sehingga berat badan berada didepan ,dan segera memasuki lapangan permainan.

\section{Pengertian Plyometric}

Latihan plyometric adalah salah satu latihan yang favorit dilakukan pelatih saat ini, terutama pada cabang olahraga yang membutuhkan kemampuan daya ledak otot tungkai atau otot lengan (Johansyah Lubis, 2005). Plyometric adalah latihan-latihan atau ulangan yang bertujuan menghubungkan gerakan kecepatan dan kekuatan untuk menghasilkan gerakan eksplosive. 


\section{Model LatihanJumping Servis Atas}

Beberapa ahli pendapat tentang jumping servis, beberapa pendapat ahli yaitu Anandita (2010: 25-26) mengatakan bahwa jump service adalah service atas dengan awalan dan cara memukul yang hampir sama. Awalan jump service melakukan melemparkan bola keatas akan tetapi tidak terlalu tinggi dari kepala, tangan yang akan memukul bola untuk bersiap di dekat bola dengan ayunan yang sangat pendek. Sejalan dengan pendapat tersebut ada ahli lain yang berpendapat tentang pengertian jump service, menurut Somantri dan Sujana (2009: 24) mengatakan bahwa " jump service adalah servis dengan awalan dan cara memukul yang hampir sama, tetapi dilakukan dengan cara melompat atau mengapung. Jump service dilakukan dengan cara melemparkan bola keatas, dan orang yang akan melakukan service melakukan melompat".

\section{Frithistis}

Gambar 2

Model Jumping Servis Atas.

Menurut (Furgon \& Doewes 2002) menyatakan bahwa latihan plyometric adalah suatu latihan yang memiliki ciri khusus, yaitu kontraksi otot yang sangat kuat yang merupakan respon dari pemberian regangan yang cepat dari otot-otot terlibat dan menghasilkan pergerakan otot isometric dan menyebabkan reflex regangan otot dalam otot.

Beberapa definisi di atas, dapat disimpulkan bahwa latihan plyometric adalah metode latihan untuk meningkatkan daya ledak otot dengan bentuk kombinasi latihan isometric dan isotonic (eksentrik/ 
konsentrik) yang mempergunakan pembebanan dinamik (Furgon \& Doewes, 2002).

Regangan yang terjadi secara mendadak sebelum otot berkontraksi kembali atau sebuah latihan yang memungkinkan otot untuk mencapai kekuatan maksimal dalam waktu yang sesingkat mungkin (Nala, 2011). Konsep latihan plyometric menggunakan regangan awal pada otot secara cepat sebelum kontraksi eksentrik pada otot yang sama (Johansyah Lubis, 2009).

Dari definisi di atas dapat dikatakan bahwa latihan plyometric adalah bentuk latihan power dengan karakteristik menggunakan kontraksi otot yang sangat kuat dan cepat, yaitu otot selalu berkontraksi baik saat memanjang (eccentric) maupun saat memendek (concentric) dalam waktu cepat, sehingga selama bekerja otot tidak ada waktu relaksasi (Hasanah, 2013). Latihan plyometric bermanfaat untuk meningkatkan reaksi syaraf otot, hubungan kekuatan dan kecepatan, dan kemampuan untuk membangkitkan gaya (tenaga) ke arah tertentu (Gomang, 2016).

Bentuk latihan plyometric yang digunakan dalam penelitian ini adalah plyometric depth jump dan Standing Jump. Latihan ini mempunyai kelebihan penekanan pada daya ledak otot tungkai yang sangat diperlukan oleh pemain bola voli untuk meningkatkan kemampuannya dalam melakukan vertical jump.

\section{METODE PENELITIAN}

Metode adalah cara atau jalan yang ditempuh untuk mencapai tujuan. Penggunaan metode yang akan dipakai dalam suatu penelitian tergantung pada tujuan yang hendak akan dicapai. Dengan kata lain metode harus dilihat dari sudut sejauh mana pengaruh, efisiensi dan relevansi terhadap masalah yang akan diteliti. Metode yang akan digunakan dalam penelitian ini adalah metode eksperimen. Tujuan penelitian eksperimen adalah untuk menilai bagaimana 
(Kodrad Budiyo, Arif Rohman Hakim)

pengaruh sebuah perilaku, terhadap kondisi suatu populasi tertentu untuk menguji hipotesis tentang ada tidaknya pengaruh perlakuan.

Penelitian ini mempunyai dua kelempok untuk diteliti, sehingga dikategorikan kedalam penelitian perbandingan (comparative experiment). Karena akan membandingkan hasil latihan plyometric hurdel hopping dengan Standing jump terhadap kemampuna jumping.

Menurut Arikunto (2006:272) penelitian eksperimen merupakan penelitian yang dimaksudkan untuk mengetahui adanya akibat atau tidak terhadap subjek yang dikenai perlakuan. Desain penelitian yang digunakan adalah two groups pre-test-post-test design,yaitu desain penelitian yang terdapat pretest sebelum diberi perlakuan dan posttest setelah diberi perlakuan, dengan demikian dapat diketahui lebih akurat, karena dapat membandingkan dengan diadakan sebelum diberi perlakuan (Sugiyono,2007:64). Adapun desain penelitian sebagai berikut:

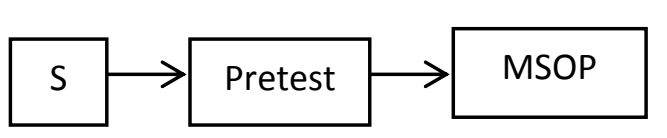

Gambar 6

Two Group Pretest-Postest Design

(Sugiyono, 2007:32)

Keterangan:

$\mathrm{S}$

Pretest $\quad$ : Tes awal kemampuan jumping servis atas10 bola

MSOP $\quad$ : Matched Subjek OrdinalPairing

KE I : Kelompok 1

KE II : Kelompok 2

Treatment A : Latihan menggunakan plyometric hurdel hopping

Treatment B : Latihan menggunakan standing jump

Posttest : : Tes akhir kemampuan jumping servis atas. 
(Kodrad Budiyo, Arif Rohman Hakim)

\section{HASIL PENELITIAN}

Pencapaian tujuan yang diinginkan dalam penelitian ini dilakukan tes Kemampuan jumping servis atas. Data yang dikumpulkan terdiri dari tes awal secara keseluruhan, kemudian dikelompokkanmenjadi dua kelompok, yaitu kelompok 1 dengan latihan Metode Latihan Plyometric Hurdle hopping, dan kelompok 2 dengan perlakuan latihan Standing Jumping, serta data tes akhir masing-masing kelompok. Data tersebut kemudian dianalisis dengan statistik $t$ test seperti terlihat pada lampiran. Rangkuman hasil analisis data secara keseluruhan disajikan dalam bentuk tabel sebagai berikut:

Tabel 1. Deskripsi Data Hasil Tes Kemampuan jumping servis atas pada Kelompok 1 dan Kelompok 2

\begin{tabular}{|c|c|c|c|c|c|c|}
\hline Kelompok & Tes & $\mathbf{N}$ & $\begin{array}{c}\text { Hasil } \\
\text { Terendah }\end{array}$ & $\begin{array}{c}\text { Hasil } \\
\text { Tertinggi }\end{array}$ & Mean & SD \\
\hline \multirow{2}{*}{ Kelompok 1 } & Awal & 15 & 7.00 & 11.00 & 8.93 & 0.91 \\
\cline { 2 - 7 } & Akhir & 15 & 28.69 & 72.78 & 50.00 & 10.00 \\
\hline \multirow{2}{*}{ Kelompok 2 } & Awal & 15 & 11.00 & 12.00 & 11.60 & 0.50 \\
\cline { 2 - 7 } & Akhir & 15 & 72.78 & 83.80 & 79.39 & 5.49 \\
\hline
\end{tabular}

Dari tabel 3 dapat diketahui bahwa sebelum diberikan perlakuan kelompok 1 memiliki rata-rata ketrampilan Kemampuan jumping servis atas sebesar 8.93, sedangkan setelah mendapatkan perlakuan memiliki rata-rata ketrampilan Kemampuan jumping servis atas sebesar 50.00. Adapun rata-rata nilai ketrampilan Kemampuan jumping servis atas pada kelompok 2 sebelum diberi perlakuan adalah sebesar 11.60, sedangkan setelah mendapatkan perlakuan memiliki rata-rata nilai ketrampilan Kemampuan jumping servis atas sebesar 79.39 .

Setelah diberi perlakuan yang berbeda yaitu, kelompok 1 diberi perlakuan dengan latihan Metode Latihan Plyometric Hurdle hopping dan kelompok 2 diberi 
(Kodrad Budiyo, Arif Rohman Hakim)

perlakuan latihan Standing Jumping, kemudian dilakukan uji perbedaan. Uji perbedaan yang dilakukan dalam penelitian ini hasilnya adalah sebagai berikut:

1. Hasil uji perbedaan tes awal dan tes akhir pada kelompok 1 yaitu:

Tabel 2. Rangkuman Hasil Uji Perbedaan Tes Awal dan Tes Akhir pada Kelompok $1\left(\mathrm{~K}_{1}\right)$

\begin{tabular}{|c|c|c|c|c|}
\hline Kelompok & $\mathrm{N}$ & Mean & $\mathrm{t}_{\text {hitung }}$ & $\mathrm{t}_{\text {tabel } 5 \%}$ \\
\hline Tes Awal & 15 & 47.795 & & \\
\cline { 1 - 3 } Tes Akhir & 15 & 80.130 & 3,5423 & 2,145 \\
\hline
\end{tabular}

Dari pengujian perbedaan dengan analisis statistik $t$-test dihasilkannilai $t_{\text {hitung }}$ pada kelompok 1 antara hasil tes awal dan tes akhir sebesar 3,5423 yang ternyata lebih besar dari pada nilai $t_{\text {tabel }}$ dengan $\mathrm{N}=15, \mathrm{db}=15-1=14$ dengan taraf signifikasi 5\% adalah sebesar 2,145, sehingga dapat disimpulkan bahwa $\mathrm{H}_{0}$ diterima, maka antara tes awal dan tes akhir pada kelompok 1 terdapat perbedaan yang signifikan setelah diberi perlakuan.

2. Hasil uji perbedaan tes awal dan tes akhir pada kelompok 2 yaitu:

Tabel3. Rangkuman Hasil Uji Perbedaan Tes Awal dan Tes Akhir pada Kelompok 2

$\left(\mathrm{K}_{2}\right)$

\begin{tabular}{|c|c|c|c|c|}
\hline Kelompok & $\mathrm{N}$ & Mean & $\mathrm{t}_{\text {hitung }}$ & $\mathrm{t}_{\text {tabel } 5 \%}$ \\
\hline Tes Awal & 15 & 52.205 & & \\
\cline { 1 - 3 } Tes Akhir & 15 & 78.660 & \multirow{2}{*}{3,5132} & 2,145 \\
\hline
\end{tabular}

Dari pengujian perbedaan dengan analisis statistik $t$-test dihasilkan nilai $t_{\text {hitung }}$ pada kelompok 2 antara hasil tes awal dan tes akhir sebesar 3,5132 yang ternyata lebih besar dari pada nilai $t_{\text {tabel }}$ dengan $\mathrm{N}=15, \mathrm{db}=15-1=14$ dengan taraf signifikasi $5 \%$ adalah sebesar 2,145, sehingga dapat disimpulkan bahwa $\mathrm{H}_{0}$ diterima, maka antara tes awal dan tes akhir pada kelompok 2 terdapat perbedaan yang signifikan setelah diberi perlakuan. 
(Kodrad Budiyo, Arif Rohman Hakim)

3. Hasil uji perbedaan tes akhir antara kelompok 1 dan kelompok 2 yaitu:

Tabel 4. Rangkuman Hasil Uji Perbedaan Tes Akhir pada Kelompok $1\left(\mathrm{~K}_{1}\right)$ dan Kelompok $2\left(\mathrm{~K}_{2}\right)$

\begin{tabular}{|c|c|c|c|c|}
\hline Kelompok & $\mathrm{N}$ & Mean & $\mathrm{t}_{\text {hitung }}$ & $\mathrm{t}_{\text {tabel 5\% }}$ \\
\hline $\mathrm{K}_{1}$ & 15 & 47.795 & & \\
\hline $\mathrm{K}_{2}$ & 15 & 52.205 & 1.1155 & 2,145 \\
\hline
\end{tabular}

Dari pengujian perbedaan dengan analisis statistik $t$-test dihasilkan nilai $t_{\text {hitung }}$ hasil tes akhir antara kelompok 1 dan kelompok 2 sebesar 1.1155 yang ternyata lebih besar dari pada nilai dan $t_{\text {tabel }}$ dengan $N=15, d b=15-1=14$ dengan taraf signifikasi $5 \%$ adalah sebesar 2,145, sehingga dapat disimpulkan bahwa $\mathrm{H}_{0}$ diterima, maka hasil tes akhir pada kelompok 1 dan kelompok 2 terdapat perbedaan yang signifikan setelah diberi perlakuan.

\section{Perbedaan persentase peningkatan}

Untuk mengetahui kelompok mana yang memiliki persentase hasil ketrampilan Kemampuan jumping servis atas yang lebih baik, diadakan perhitungan persentase peningkatan tiap-tiap kelompok. Adapun nilai perbedaan ketrampilan Kemampuan jumping servis atas dalam persen pada kelompok 1 dan kelompok 2 adalah:

Tabel 5. Rangkuman Hasil Uji Perbedaan Tes Akhir pada Kelompok $1\left(K_{1}\right)$ dan Kelompok $2\left(\mathrm{~K}_{2}\right)$

\begin{tabular}{|c|c|c|c|c|c|}
\hline Kelompok & $\mathrm{N}$ & MeanPretest & MeanPosttest & MeanDifferent & $\begin{array}{c}\text { Persentase } \\
\text { Peningkatan } \\
(\%)\end{array}$ \\
\hline $\begin{array}{c}\text { Kelompok } \\
1\end{array}$ & 15 & 47.795 & 52.205 & 47.795 & $67.652 \%$ \\
\hline $\begin{array}{c}\text { Kelompok } \\
2\end{array}$ & 15 & 80.130 & 78.660 & 52.205 & $50.676 \%$ \\
\hline
\end{tabular}


Dari hasil di atas dapat diketahui bahwa kelompok 1 memiliki persentase ketrampilan Kemampuan jumping servis atas sebesar $67.652 \%$, angka kelompok 2 memiliki persentaseketrampilan Kemampuan jumping servis atas sebesar 50.676\%. Dengan demikian dapat disimpulkan bahwa kelompok 2 memiliki persentase ketrampilan Kemampuan jumping servis atas yang lebih besar dari pada kelompok 1.

\section{PEMBAHASAN}

Dari hasil uji perbedaan yang dilakukan terhadap tes akhir pada kelompok 1 dan 2, diperoleh nilai t sebesar 1.1155. Ternyata lebih kecil dari angka batas penolakan hipotesis nol. Dengan demikian hipotesis nol ditolak, yang berarti bahwa terdapat perbedaan yang signifikan antara peningkatan Pukulan pada kelompok 1 dan kelompok 2. Sedangkan $t_{\text {tabel }}=2,145$. Ternyata $t$ yang diperoleh $>\mathrm{t}$ dalam tabel, yang berarti hipotesis nol diterima. Dengan demikian dapat disimpulkan bahwa setelah diberikan perlakuan selam 6 minggu, terdapat perbedaan yang signifikan antara hasil tes awal dan tes akhir pada kelompok 1 dan kelompok 2. karena sebelum diberikan perlakuan kedua kelompok berangkat dari titik tolak yang sama, maka perbedaan tersebut adalah karena pengaruh dari metode yang diberikan.

Dalam pelaksanaan metode latihan bahwa pengaruh metode yang digunakan adalah bersifat khusus,sehingga perbedaan karakteristik metode dapat menghasilkan pengaruh yang berbeda pula. Oleh karena itu, kelompok yang diberikan perlakuan latihan Metode Latihan Plyometric Hurdle hopping dan latihan Standing Jumping, memiliki pengaruh yang berbeda terhadap hasil peningkatan ketrampilan Kemampuan jumping servis atas. Dengan demikian hipotesis yang menyatakan bahwa ada perbedaan pengaruh setelah diberikan perlakuanantara latihan Metode Latihan Plyometric Hurdle hoppingdan latihan Standing Jumpingterhadap peningkatan hasil belajar Kemampuan jumping servis atas dalam permainan bolavoli, dapat diterima kebenarannya. 


\section{SIMPULAN DAN SARAN}

\section{A. Simpulan}

Berdasarkan hasil penelitian dan hasil analisis data yang telah dilakukan, dapat diperoleh simpulan sebagai berikut:

1. Ada perbedaan Pengaruh Latihan Metode Latihan Plyometric Hurdle hopping Dan Standing Jumping Terhadap Kemampuan jumping servis atas Dalam Permainan Bola Voli Pada Atlit Putra Usia 15-17 Club Bola Voli DIVKRA Karanganyar Tahun 2020. Hal ini dibuktikan dari hasil penghitungan tes akhir masing-masing kelompok yaitu $t_{\text {hitung }}=3,5423$ lebih besar dari pada $t_{\text {tabel }}=2,145$ dengan taraf signifikasi $5 \%$.

2. Latihan Plyometric Hurdle hopping lebih baik pengaruhnya dari pada latihan Metode Latihan Standing Jumping Terhadap Kemampuan jumping servis atas Dalam Permainan Bola Voli Pada Atlit Putra Usia 15-17 Club Bola Voli DIVKRA Karanganyar Tahun 2020.

3. Berdasarkan persentase peningkatan ketrampilan Kemampuan jumping servis atas menunjukkan bahwa kelompok 1 (kelompok yang mendapat perlakuan dengan Pengaruh Latihan Metode Latihan Plyometric Hurdle hopping) adalah 67.652\%> kelompok 2 (kelompok yang mendapat perlakuan Pengaruh Latihan Standing Jumping) adalah 50.676\%.

B. Saran

Sehubungan dengan kesimpulan yang telah diambil dan implikasi yang ditimbulkan, maka kepada para pelatih, disarankan hal-hal sebagai berikut:

1. Upaya untuk meningkatan ketrampilan kemampuan jumping servis atas, hendaknya pelatih harus memiliki kreatifitas dan mampu menerapkan metode latihan yang tepat agar diperoleh hasil latihan yang optimal.

2. Dari hasil penelitian ini dapat dijadikan pedoman untuk menentukan dan memilih metode latihan untuk keterampilan Kemampuan jumping servis atas Pada Atlit Putra Usia 15-17 Club Bola Voli DIVKRA Karanganyar Tahun 2020. 
(Kodrad Budiyo, Arif Rohman Hakim)

3. Untuk peningkatan Keterampilan Kemampuan jumping servis atas Pada Atlit Putra Usia 15-17 Club Bola Voli DIVKRA Karanganyar Tahun 2020, pelatih dapat menerapkan latihan Metode Latihan Plyometric Hurdle hopping dan latihan Standing Jumping bagi para pemain.

\section{DAFTAR PUSTAKA}

Anandita. (2010). Mengenal Olahraga Voli. Bogor: Quadra.

Arikunto. Suharsimi (2006).Prosedur Penelitian Suatu Pendekatan Praktek. Jakarta:PT. Rineka cipta.Azwar,s.2000.

J Lubis. (2009). Mengenal Latihan Pliometrik. Jakarta: Universitas Negeri Jakarta.

Nala. (2011). Prinsip Pelatihan Fisik Olahrga. Denpasar: Universitas Udayana.

Subroto dan Yudiana. (2010). Permainan Bolavoli.Bandung: Universitas Pendidikan Indonesia.

Sugiyono. (2007). Metode Penelitian Kuantitatif, Kualitatif, dan R\&D. Bandung: Alfabet

Yudiana dan Subroto. (2010). Permainan Bola Voli. Bandung: FPOK Universitas Pendidikan Indonesia.

Gomang Genurianto (2016). MENINGKATKAN POWER OTOT TUNGKAI MELALUI LATIHAN PLYOMETRIC DEPTH JUMP MODIFICATION PADA PESILAT REMAJA PUTRA PERGURUAN SILAT PERSINAS ASAD SLEMAN. Jurnal Pendidikan Jasmani Kesehatan dan Rekreasi. Vol V, No 6 Tahun 2016

Hasanah, Mufidatul. 2013. Pengaruh Latihan Pliometrik Depht Jump Dan Jump To Box Terhadap Power Otot Tungkai Pada Atlet Bolavolli Klub Tugumuda Kota Semarang. Skripsi. Universitas Negeri Semarang. 